the recent discovery at Tell Duweir of an earlier manifestation of a similar school of artistic production. Among the subjects here represented are Egyptian gods, cherubim, the winged sphinx, palms and lilies. In addition to the antiquities, a large series of photographs is shown, which gives a comprehensive view of the chronological range and the extent of the excavations, as well as of the character of the objects found.

\section{New Aeroplane for England to Melbourne Race}

THE first flights of a new racing monoplane, known as the Comet, designed and built by Messrs. De Havilland for the England to Melbourne race, have just taken place at Hatfield. These preliminary trials were successful, and there is every reason to believe that the machine will be ready for its official airworthiness tests in what is probably a record time, the decision to produce the machine having been made only in January last. Three machines of the type have been built, all of which are entered for the race. The most outstanding feature of the design is the thin tapering wing, in which all the shear stresses are taken by the wooden skin covering. This idea is not entirely new, but its use has been developed much further in this case than hitherto. The wing, entirely of wood, consists of one main girder member made up with three spars, distanee pieces giving a cellular construction, and an amalgamating skin of thickness varying to suit the stresses applied. A leading and trailing edge are attached to complete the aerofoil form. The two pilots are placed well behind the wing, with the main fuel tanks filling the body in front of them. A further smaller tank occupies the space behind them. Two special Gipsy Six (230 H.P.) engines are placed outboard, practically buried in the wings, with such parts as are necessarily protruding below, carefully cowled. The undercarriage legs are masked behind the engines so far as possible, and the lower portions are retracted to the same space during flight.

\section{Sting of Hive-Bees}

The point raised by Dr. J. G. Myers, in Nature of August 25, p. 290, regarding the ability of the hive-bee to withdraw its sting, is not a new one, and has elicited a letter of protest from a practical beekeeper, Mr. Z. B. H. Garrett, of Ingoldsby, Longfield, Kent, When bees are 'induced to sting' experimentally, they frequently extricate the sting as soon as the pressure or other inducement is relaxed. Naturally a bee can withdraw its sting from the soft tissues of, say, a wax-moth larva more easily than from the thumb of the experimenter. Another point which is generally overlooked is the age of the stinging bee. Up to three days or more after emergence, young bees can scarcely be persuaded to use their stings. The typical stinging age, as was first shown by Rosch, is towards the end of the period of domestie duties, and on the eve of the outdoor foraging period. It is reasonable to surmise that the sting glands reach their maximum development at this period of the bee's life, just as the lateral pharyngeal glands do at a somewhat earlier stage-possibly to atrophy, as do the latter with advancing age. The stings received by the beekeeper as one of the hazards of his calling are given with a will by the guard bees, which are physiologically ripe for the job. Such bees make for the eyelids, nose, or the back of the neck, and seldom attempt to remove their stings, though the beekeeper should make a point of doing so, without squeezing the venom sac, at the earliest opportunity. It is otherwise with those bees that crawl up the sleeves or trouser legs. These have no malice prepense, and do not use their stings until they find themselves trapped by the pressure of the clothing or nervous movements on the part of the beekeeper. Such bees, if undamaged and given time, can often withdraw their stings and be coaxed out towards the light.

\section{Mechanical Weather Forecasting}

"Dr. CurRy's weather prophet" is an attractive aluminium instrument, light in weight, circular in shape, and thin enough to go easily into the pocket, which is being marketed in England by W. B. M. Unland, 72 Leadenhall Street, London, E.C.3. The face of the disc is adorned with a ring of coloured slips, ranging from a deep mystical blue, like the blue of the sky seen from a high mountain, through violet to a pinkish hue. In the centre of the disc is a tiny, restless compass. The tale of magic is not yet done: there are two little fairy casements. Through one, when the stage is set, can be seen a letter telling of the direction of the wind, and through the other, Dr. Curry's weather prediction in plain black print, an austerely definite pronouncement. According to an experienced motor salesman, the public estimates the value of a motor-car by the array of instruments on the dashboard. Dr. Curry, or if not Dr. Curry, then the instrument designer who has given his idea practical shape, is evidently an equally profound student of ill-informed, would-beexpert humanity. Here is an instrument of character and charm which makes the more expensive forecasting aneroid barometer look as though it should cost far less. The price is $6 s$. $8 d$., and for an extra shilling the weather wisdom of the aneroid is 'thrown in' by a simple device. If mass production could bring the price even lower it might take even the South Sea Islands by storm, not because it is a praiseworthy attempt to get automatically a useful forecast from the observed direction of the wind and the relative humidity as shown by the hue of a chemically-treated slip, but because it is impossible for any human being to see one without being impelled to find out what it is all about.

\section{Pulpwood for Paper in the United States}

A LARGE amount of American capital has been employed for building newsprint mills in Canada. Recently, attention has been directed to the great pine forests in the Southern States and their suit. ability for making pulp for newsprint is being investigated. In the Scientific American of May, 1934, an interesting account is given by Dr. Herty of what is being done in this direction. It is pointed out that 